\title{
Recurrent genomic alterations in benign and malignant pheochromocytomas and paragangliomas revealed by whole-genome array comparative genomic hybridization analysis
}

\author{
Johanna Sandgren ${ }^{1,2}$, Teresita Diaz de StåhP', Robin Andersson ${ }^{3}$, Uwe Menzel' ${ }^{2}$, \\ Arkadiusz Piotrowski ${ }^{4}$, Helena Nord ${ }^{2}$, Martin Bäckdahl ${ }^{5}$, Nimrod B Kiss. ${ }^{5}$, \\ Michael Brauckhoff ${ }^{6}$, Jan Komorowski $i^{3}$, Henning Dralle ${ }^{6}$, Ola Hessman ${ }^{1}$, \\ Catharina Larsson ${ }^{5}$, Göran Ákerström ${ }^{1}$, Carl Bruder ${ }^{7}$, Jan P Dumanski ${ }^{2}$ \\ and Gunnar Westin'
}

\footnotetext{
${ }^{1}$ Department of Surgical Sciences, Uppsala University Hospital and ${ }^{2}$ Rudbeck Laboratory, Department of Genetics and Pathology, Uppsala University, SE-751 85 Uppsala, Sweden

${ }^{3}$ Department of Cell and Molecular Biology, The Linnaeus Centre for Bioinformatics, Uppsala University, SE-751 24 Uppsala, Sweden

${ }^{4}$ Department of Biology and Pharmaceutical Botany, Medical University of Gdansk, Hallera 107, 80-416 Gdansk, Poland

${ }^{5}$ Department of Molecular Medicine and Surgery, Karolinska Institutet, Stockholm, Sweden

${ }^{6}$ Department of General, Visceral and Vascular Surgery, Martin Luther University of Halle, 06099 Halle, Germany

${ }^{7}$ Southern Research Institute, 2000 Ninth Avenue South, Birmingham, Alabama 35205-5305, USA
}

(Correspondence should be addressed to J Sandgren at Rudbeck Laboratory, Department of Genetics and Pathology, Uppsala University; Email: johanna.sandgren @ surgsci.uu.se; G Westin at Department of Surgical Sciences, Uppsala University Hospital, Uppsala University; Email: gunnar.westin@surgsci.uu.se)

\begin{abstract}
Pheochromocytomas and abdominal paragangliomas are adrenal and extra-adrenal catecholamine-producing tumours. They arise due to heritable cancer syndromes, or more frequently occur sporadically due to an unknown genetic cause. The majority of cases are benign, but malignant tumours are observed. Previous comparative genomic hybridization (CGH) and loss of heterozygosity studies have shown frequent deletions of chromosome arms $1 p, 3 q$ and $22 q$ in pheochromocytomas. We applied high-resolution whole-genome array $\mathrm{CGH}$ on 53 benign and malignant pheochromocytomas and paragangliomas to narrow down candidate regions as well as to identify chromosomal alterations more specific to malignant tumours. Minimal overlapping regions (MORs) were identified on 16 chromosomes, with the most frequent MORs of deletion $(\geq 32 \%$ ) occurring on chromosome arms $1 p, 3 q, 11 p / q, 17 p$ and $22 q$, while the chromosome arms $1 q, 7 p, 12 q$ and $19 p$ harboured the most common MORs of gain $(\geq 14 \%)$. The most frequent MORs $(61-75 \%)$ in the pheochromocytomas were identified at $1 \mathrm{p}$, and the four regions of common losses encompassed 1p36, 1p32-31, 1p22-21 and 1p13. Tumours that did not show $1 p$ loss generally demonstrated aberrations on chromosome 11. Gain of chromosomal material was significantly more frequent among the malignant cases. Moreover, gain at 19q, trisomy 12 and loss at $11 \mathrm{q}$ were positively associated with malignant pheochromocytomas, while 1q gain was commonly observed in the malignant paragangliomas. Our study revealed novel and narrow recurrent chromosomal regions of loss and gain at several autosomes, a prerequisite for identifying candidate tumour suppressor genes and oncogenes involved in the development of adrenal and extra-adrenal catecholamine-producing tumours.
\end{abstract}

Endocrine-Related Cancer (2010) 17 561-579 


\section{Introduction}

A pheochromocytoma is a rare endocrine tumour predominately arising from the catecholamineproducing chromaffin cells in the adrenal medulla. In $10-23 \%$ of cases, tumours occur in extra-adrenal locations in sympathetic paraganglia, and are therefore often termed as extra-adrenal pheochromocytomas or paragangliomas (Erickson et al. 2001, Bravo \& Tagle 2003, Karagiannis et al. 2007). Paraganglioma, however, refers to all neoplasias of the paraganglion nervous system, consisting of both sympathetic and parasympathetic paraganglia located along the large vessels from the base of the skull to the pelvis. Paragangliomas of the parasympathetic nervous system are mostly situated in the head and neck region, and very rarely secrete significant amounts of catecholamines (Karagiannis et al. 2007).

Around $10-25 \%$ of pheochromocytomas develop due to the presence of constitutional mutations in any of the seven susceptibility genes, which give rise to different familial syndromes (Karagiannis et al. 2007). Mutations in RET, VHL and NFI cause multiple endocrine neoplasia type 2, von Hippel-Lindau disease and neurofibromatosis type 1 respectively (Xu et al. 1992, Latif et al. 1993, Mulligan et al. 1993), whereas germline mutations in $S D H B, S D H C, S D H D$ and $S D H 5$ genes have been found in paraganglioma syndromes (Baysal et al. 2000, Niemann \& Muller 2000, Astuti et al. 2001a,b, Eng et al. 2003, Hao et al. 2009). However, the majority of pheochromocytomas occur sporadically with more or less unknown genetic background. The sporadic tumours rarely display somatic mutations in the genes associated with familial disease (Dannenberg et al. 2003). Most tumours are benign, but malignant pheochromocytomas have been reported to comprise up to $10 \%$ of all cases (Bravo \& Tagle 2003, Elder et al. 2005, Karagiannis et al. 2007). Malignant tumours occur, however, more frequently among abdominal paragangliomas, representing $\sim 20 \%$ of these cases (Linnoila et al. 1990). Distinguishing between benign disease and malignant disease is notoriously difficult, and current WHO classification recognizes the presence of metastases as the only reliable criterion for malignancy, whereas others also accept local invasion or recurrence in tissue where chromaffin cells do not normally exist (Neumann et al. 2002, Bryant et al. 2003, Strong et al. 2008, Tischler 2008). Therefore, there is a great need for novel markers that could improve the ability to predict and treat malignant disease.

A frequent finding in solid tumours is the presence of DNA copy number aberrations that can contribute to tumour development by inducing chromosomal instability and changes in gene expression (Hughes et al. 2000, Pollack et al. 2002, Kallioniemi 2008). Cytogenetic, molecular and array-based methods are used to study these alterations. Loss of heterozygosity (LOH) and metaphase/array comparative genomic hybridization (CGH) studies have reported loss of chromosome arms 1p, 3p/q, 11p/q, 17p and 22q as frequent events in pheochromocytomas, indicating the potential presence of tumour suppressor genes on these autosomes. Gain of chromosomal material has appeared less frequently, and the most commonly affected chromosomal regions include 1q, 12q, 17q, 19p/q and 20q (Bender et al. 2000, Edstrom et al. 2000, August et al. 2004, Cascon et al. 2005, Jarbo et al. 2006, Aarts et al. 2006, van Nederveen et al. 2009). Here, we have used a high-resolution whole-genome tiling array, consisting of more than 32000 BAC (bacterial artificial chromosome) clones (32K array), to comprehensively characterize the DNA copy number status of 44 adrenal pheochromocytomas and 9 sympathetic paragangliomas. Available corresponding blood or normal tissues from 36 samples were concomitantly evaluated on this array platform.

\section{Materials and methods}

\section{Samples}

A total of 53 tumour samples and 36 paired normal adrenal tissue and/or blood samples were used in the study (Table 1). Of these tumours, 44 were pheochromocytomas and 9 were paragangliomas, i.e. sympathetic, catecholamine-producing tumours with abdominal localization. The tumour cell content in the samples was confirmed by an experienced pathologist. Four of the pheochromocytomas and six of the paragangliomas were classified as malignant due to the presence of metastases, whereas four and one respectively were considered malignant due to invasive behaviour of the primary tumour or recurrence with invasion. One patient presented extensive tumour thrombosis (Table 2). Two of the apparently benign pheochromocytomas (samples 36 and 37) were analysed separately from the rest of the benign tumours due to the following histological characteristics: large tumour size $(10 \mathrm{~cm})$ and atypical histological features for one sample, and moderate size $(4 \mathrm{~cm})$, but marked atypia, presence of necroses and spread mitoses for the other sample (Tumour $36,4 \mathrm{~cm}$ large pheochromocytoma with capsular and intratumoural vascular invasion, occasional mitoses, no metastases during 13 years of follow-up. Tumour $37,10 \mathrm{~cm}$ large 


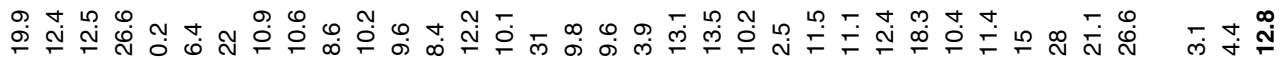

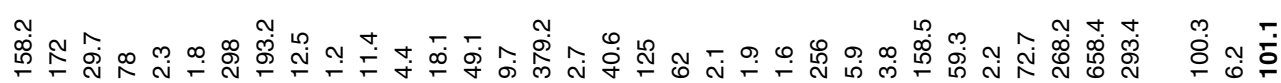
in 늠 命

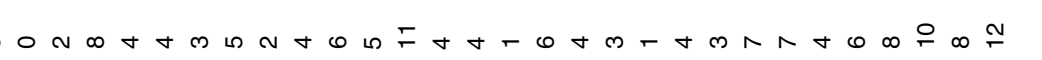
$-$

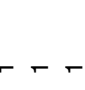
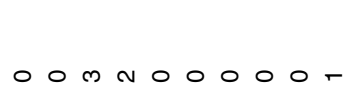


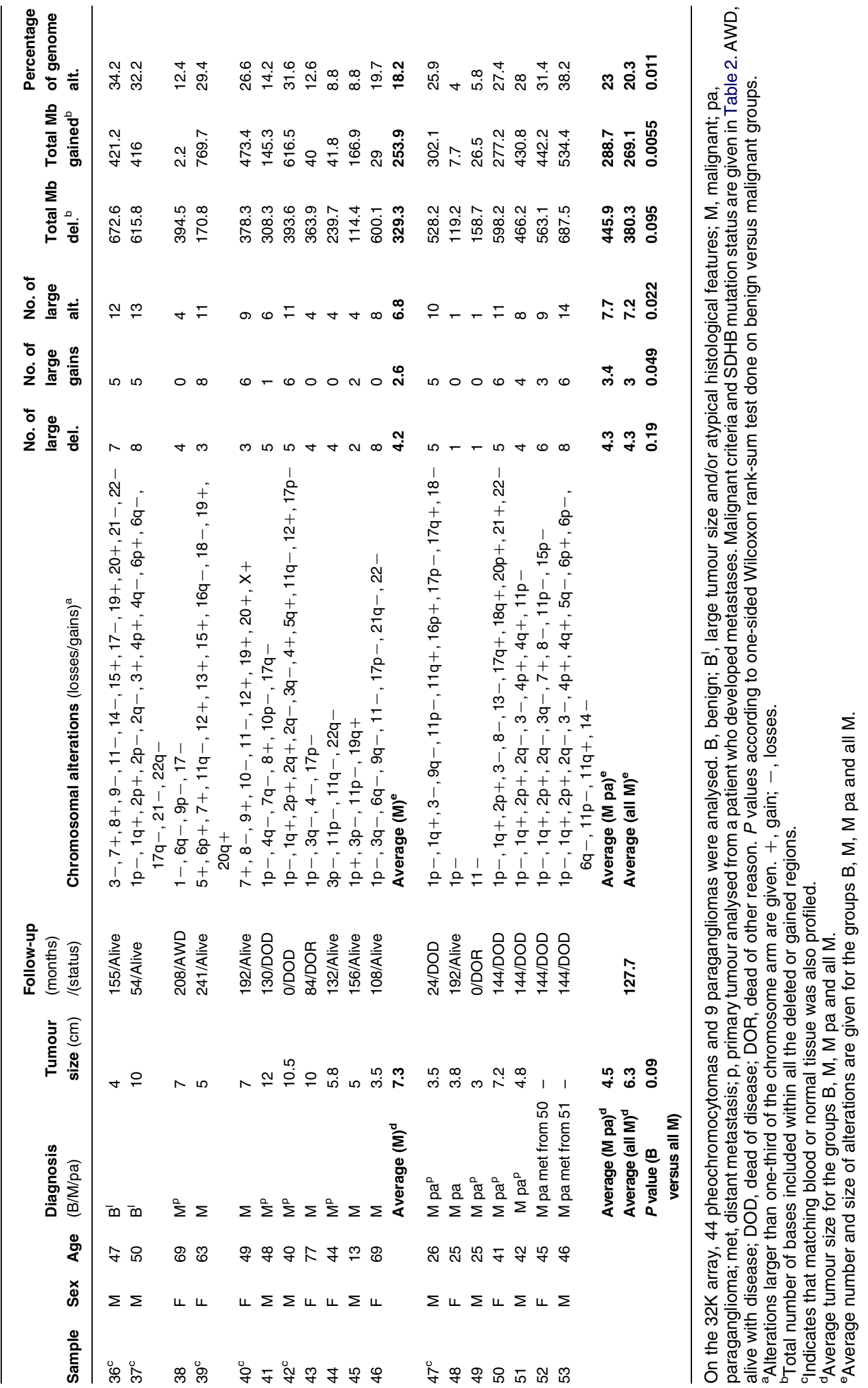


Table 2 Criteria for malignancy and SDHB mutation analysis of all 16 malignant tumours and paragangliomas

\begin{tabular}{|c|c|c|c|c|c|}
\hline \multirow[b]{2}{*}{ Sample } & \multirow[b]{2}{*}{ M/M pa/B pa } & \multirow[b]{2}{*}{ Criteria for malignancy } & \multicolumn{3}{|c|}{ SDHB sequencing results } \\
\hline & & & SDHB sequence & $\begin{array}{l}\text { Polymorphism (p) } \\
\text { /mutation (m) }\end{array}$ & Location \\
\hline \multirow[t]{4}{*}{38} & $M^{a}$ & Multiple recurrences, & c. $18 \mathrm{C}>\mathrm{A}$ & $p$ & p.6A6 \\
\hline & & metastases during & c. $200+33 G>A$ & $\mathrm{p}$ & Intron \\
\hline & & follow-up & $c 201-36 G>T$ & $p$ & Intron \\
\hline & & & c. $487 \mathrm{~T}>\mathrm{C}$ & $\mathrm{p}$ & p.S163P \\
\hline \multirow[t]{3}{*}{39} & M & Local recurrence, invasive & c. $18 \mathrm{C}>\mathrm{A}$ & $\mathrm{p}$ & p.6A6 \\
\hline & & & c. $200+35 G>A$ & $p$ & Intron \\
\hline & & & $\mathrm{c} 201-36 \mathrm{G}>\mathrm{T}$ & $\mathrm{p}$ & Intron \\
\hline \multirow[t]{4}{*}{40} & M & Local recurrence, invasive & c. $18 \mathrm{C}>\mathrm{A}$ & $\mathrm{p}$ & p.6A6 \\
\hline & & & $\mathrm{c} 200+33 \mathrm{G}>\mathrm{A}$ & $p$ & Intron \\
\hline & & & c. $201-36 \mathrm{G}>\mathrm{T}$ & $p$ & Intron \\
\hline & & & $\mathrm{c} 468 \mathrm{~T}>\mathrm{C}$ & $\mathrm{p}$ & p.S163P \\
\hline \multirow[t]{2}{*}{41} & $M^{a}$ & Metastases & c. $18 \mathrm{C}>\mathrm{A}$ & $\mathrm{p}$ & p.6A6 \\
\hline & & & c. $201-36 \mathrm{G}>\mathrm{T}$ & $\mathrm{P}$ & Intron \\
\hline 42 & $M^{a}$ & Metastases & wt & - & - \\
\hline 43 & M & Invasive & wt & - & - \\
\hline 44 & $M^{a}$ & Metastases, local recurrence & wt & - & - \\
\hline 45 & $M$ & Tumour thrombosis & wt & - & - \\
\hline 46 & M & Invasive & wt & - & - \\
\hline 47 & $\mathrm{Mpa}^{\mathrm{a}}$ & Metastases & c.151_154insGACA & $\mathrm{m}$ & Exon 2 \\
\hline 48 & M pa & Invasive, local recurrence & c.151_154insGACA & $\mathrm{m}$ & Exon 2 \\
\hline 49 & $\mathrm{Mpa}^{\mathrm{a}}$ & Metastases & wt & - & - \\
\hline 50 & $\mathrm{M} \mathrm{pa}^{\mathrm{a}}$ & Metastases, local recurrence & c. $423+1 \mathrm{G}>\mathrm{A}$ & $\mathrm{m}$ & Splice site \\
\hline 51 & M pa & $\begin{array}{l}\text { Invasive, metastases, local } \\
\text { recurrence }\end{array}$ & wt & - & - \\
\hline 52 & M pa met from 50 & Metastases, local recurrence & c. $423+1 \mathrm{G}>\mathrm{A}$ & $\mathrm{m}$ & Splice site \\
\hline 53 & M pa met from 51 & $\begin{array}{l}\text { Invasive, metastases, local } \\
\text { recurrence }\end{array}$ & wt & - & - \\
\hline 34 & B pa & & wt & - & - \\
\hline 35 & $\mathrm{~B}$ pa & & c. $190 \mathrm{delG}$ & $\mathrm{m}$ & Exon 1 \\
\hline
\end{tabular}

M, malignant; B, benign; pa, paraganglioma; met, distant metastasis. a primary tumour analysed from a patient who developed metastases. The SDHB mutation analysis of samples $42-53$ and 34-35 was done according to that described in Kiss et al. (2008).

pheochromocytoma with necroses, spread mitoses and marked nuclear pleomorphism, with bizarre nuclear variations, no metastases during 5 years of follow-up). In two of the cases with malignant paragangliomas, both the primary metastasis and the associated metastasis were studied. The samples were collected in tissue banks during a 20-year period from the Uppsala University Hospital (24 tumours, 13 normal tissues and 7 blood samples), the Karolinska University Hospital (24 tumours and 13 blood samples) (Edstrom Elder et al. 2003) and the Halle University Hospital, Germany (5 tumours and 3 blood samples). Samples were collected with informed consent from the patients, and the study of samples was approved by the respective local ethics committees. Standard methods were used to extract DNA. The reference DNA used in all the hybridization experiments was derived from peripheral leucocytes of a healthy female (de Stahl et al. 2008).

On average, patients with benign tumours were followed up for 124 months (range 16-240), and patients with malignant tumours were followed up for 128 months (range 0-241) (Table 1).

Based on careful family history and clinical findings, cases with MEN2, VHL and NF1 familial syndromes were not included in the study. Mutation in the succinate dehydrogenase complex, subunit $\mathrm{B}$, iron sulphur (Ip) gene (SDHB, PGL4) is relatively common in malignant pheochromocytomas and paragangliomas (Neumann et al. 2004, Pasini \& Stratakis 2009), and mutation analysis of SDHB was performed in all paragangliomas and all malignant pheochromocytomas (samples 34, 35 and 38-53, Table 2). Sequence analysis of the $S D H B$ gene was done as described (Kiss et al. 2008).

\section{Hybridization on 32K BAC array}

Array construction is outlined in previous reports (Piotrowski et al. 2008, de Stahl et al. 2008). DNA labelling, hybridization, washing and scanning were 
performed as described previously with minor modifications (Buckley et al. 2002). In short, $1.5 \mu \mathrm{g}$ of genomic test and reference DNA were labelled using random primers (BioPrime Array CGH Genomic Labeling kit, Invitrogen) and Cy3CTP (PA53021, GE HealthCare, Chalfont St Giles, Buckinghamshire, UK) and Cy5 (PA55021, GE HealthCare). Purified probe DNA was mixed with $150 \mu \mathrm{g}$ human COT-1 DNA, vacuum evaporated and resuspended in $50 \mu \mathrm{l}$ of hybridization solution (50\% formamide, 5\% SDS; $10 \%$ dextran sulphate, M.W. 500000, $2 \times$ SSC). The mixture was then denaturated for $5 \mathrm{~min}$ at $95^{\circ} \mathrm{C}$ and incubated for $2 \mathrm{~h}$ at $45^{\circ} \mathrm{C}$ before being applied to the array and covered by a lifterslip. Hybridization was carried out at $45^{\circ} \mathrm{C}$ for $20 \mathrm{~h}$ in slide chambers (Corning Inc., New York, NY, USA). The slides were washed in $25 \%$ formamide, $2 \times \mathrm{SSC}, 0.1 \%$ SDS at $45^{\circ} \mathrm{C}$ for $17 \mathrm{~min}$ followed by washing for $10 \mathrm{~min}$ in $1 \times$ PBS at room temperature, rinsed in $\mathrm{H}_{2} \mathrm{O}$ for a few seconds and immediately blow-dried using pressurized dust-free air.

\section{Data analysis and statistics}

Image capture and detection of $\mathrm{Cy} 5$ and $\mathrm{Cy} 3$ intensities for each spot on the arrays were performed using GenePix 4000B scanner (Axon Instruments Inc., Union City, CA, USA), and acquired data were analysed using GenePix Pro v6 image analysis software (Axon Instruments). Raw data files were uploaded to and stored in a LIMS database, hosted by Linnaeus centre for Bioinformatics (LCB, base.lcb.uu.se). Filtration, normalization and statistical analysis of the data were performed with tools developed by LCB (LCB-DWH, http://dw.lcb.uu.se; Ameur et al. 2006). Oversaturated spots, spots with low signal-to-noise ratio $(\mathrm{SNR}<3)$ in either channel and spots manually or automatically flagged as bad or absent in GenePix Pro were filtered out. Print-tip loess normalization was applied to adjust for dye bias and/or spatial effects. The classification of clones as gained, deleted or balanced level was done using SMAP (segmental maximum a posteriori) (Andersson et al. 2008). For a specified number of states, SMAP iteratively fits a hidden Markov model genome wide to the data, and infers the most probable profile of copy numbers for each chromosome using a segmental a posteriori approach until no further improvements can be made. Each individual clone was subsequently assigned a copy number class (CNC): 1, gain; -1 , deleted or 0 , balanced. If so, $\mathrm{CNCs}$ for homozygous deletion $(\mathrm{CNC}=-2)$ and for more than two copies gained $(\mathrm{CNC} \geq 2)$ were also considered. Single clones with a CNC different from that of the neighbouring clones were re-assigned to the $\mathrm{CNC}$ of the neighbouring clones. The resulting genomic profiles are visualized using a graphical tool that plots all clones according to their chromosomal position and ratio, coloured according to their CNC status. Clone mapping information was obtained from ensemble (http://ensemble.org/biomart).

A one-sided Wilcoxon rank-sum test was done to assess for differences in the number of alterations and megabases $(\mathrm{Mb})$ of genome altered as well as for differences in tumour size between the benign and malignant tumours. Identification of clones more often associated with aberrations in the malignant versus benign pheochromocytomas and between malignant pheochromocytomas and malignant primary paragangliomas was performed using Fisher's exact test on the $\mathrm{CNC}$ data. The test was used to evaluate statistical differences between gained and not gained clones, as well as between deleted and not deleted clones in the tumour groups. The clones were ranked according to their $P$ value, and $P<0.05$ was considered as a cut-off for significant overrepresentation in that group. The web-based Gene Ontology (GO) analysis tool DAVID (http://david.abcc.ncifcrf.gov/) was used for functional annotation analysis and for the determination of statistical overrepresentation of GO terms among genes encompassed within candidate regions. For all analyses, the GO term Biological Process was considered.

\section{Quantitative PCR}

Quantitative PCR (qPCR) quantification of the relative DNA copy number was performed using SYBR Green detection chemistry and a standard curve method as described by Applied Biosystems (ABI user bulletin \#2) (Carlsbad, CA, USA). A standard curve was generated from threefold DNA dilution series of a normal human genomic DNA (Applied Biosystems, P/N 4312660) to produce six quantities ranging from 0.123 to $30 \mathrm{ng}$ of human DNA. The primer efficiency was calculated using the formula: $E \%=\left(10^{(-1 / \text { slope })-1}\right) \times 100 \%$. A total of three regions on chromosome 13 and chromosome 14 that showed stable copy numbers were selected as calibrators for normalization of copy number ratio. The relative fold increase in copy number was interpolated from the calibration curve upon normalization of the amount of DNA of the gene of interest to that of the calibrator. The results were analysed according to the Applied Biosystems user manual in Microsoft Excel. 


\section{Results}

\section{$32 \mathrm{~K}$ profiling of copy number alterations in pheochromocytomas and paragangliomas}

The alterations detected in the panel of 53 tumours studied involved losses and gains of whole chromosomes as well as copy number imbalances restricted to specific regions. Representative $32 \mathrm{~K}$ whole-genome profiles of a benign and a malignant sample from two different patients are shown in Fig. 1, and a whole-genome overview of DNA copy number alterations for each analysed tumour sample is displayed in Supplementary Figure S1, see section on supplementary data given at the end of this article. The number of large alterations per tumour, defined as affecting more than one-third of a chromosome arm, was variable and ranged from 0 to 14 . Gains and losses were found on all autosomes, with the latter event being more common. No tumour-specific homozygous deletions or amplicons ( $>3$ copies) were found in the studied samples. A list of large chromosomal aberrations present in each tumour and patient data are presented in Table 1. Copy number variations detected in constitutional DNA (peripheral leucocytes or normal tissue) overlapped with known copy number variations according to the Database of Genomic Variants (http:// projects.tcag.ca/variation), and none appeared to be disease specific. We compared the number of large alterations present in benign (33 pheochromocytomas and 2 paragangliomas) versus malignant tumours (9 pheochromocytomas and 7 paragangliomas), and found that the latter group had significantly more alterations. On average, malignant samples presented with 7.2 alterations versus 4.9 presented by benign tumours (Table 1). Significantly, more regions of gain were found in the former group (3.0 vs 1.2), though the number of large deletions was similar for the malignant and benign groups (4.3 vs 3.7). We also calculated the fraction of the genome affected by DNA copy number changes for each tumour, including large and small alterations, and found that the average fraction of DNA copy number alterations was significantly higher for the malignant pheochromocytomas/paragangliomas than for the benign tumours (20.3 vs $12.8 \%$, Table 1$)$. Correlation analyses (Spearman) revealed no relationship between tumour size and any chromosomal alteration (data not shown). In addition, no significant trend for a larger tumour in the malignant group was found (Table 1). Moreover, no relationship with patients' sex was disclosed (Fisher's test, data not shown).

To assess common chromosomal aberrations, most likely important for tumour development, we generated frequency plots that visualize the occurrence of DNA copy number changes for each BAC on the array for the benign pheochromocytomas, malignant pheochromocytomas and malignant paragangliomas (Fig. 2). The most recurrent DNA copy number change observed in benign pheochromocytomas was loss of
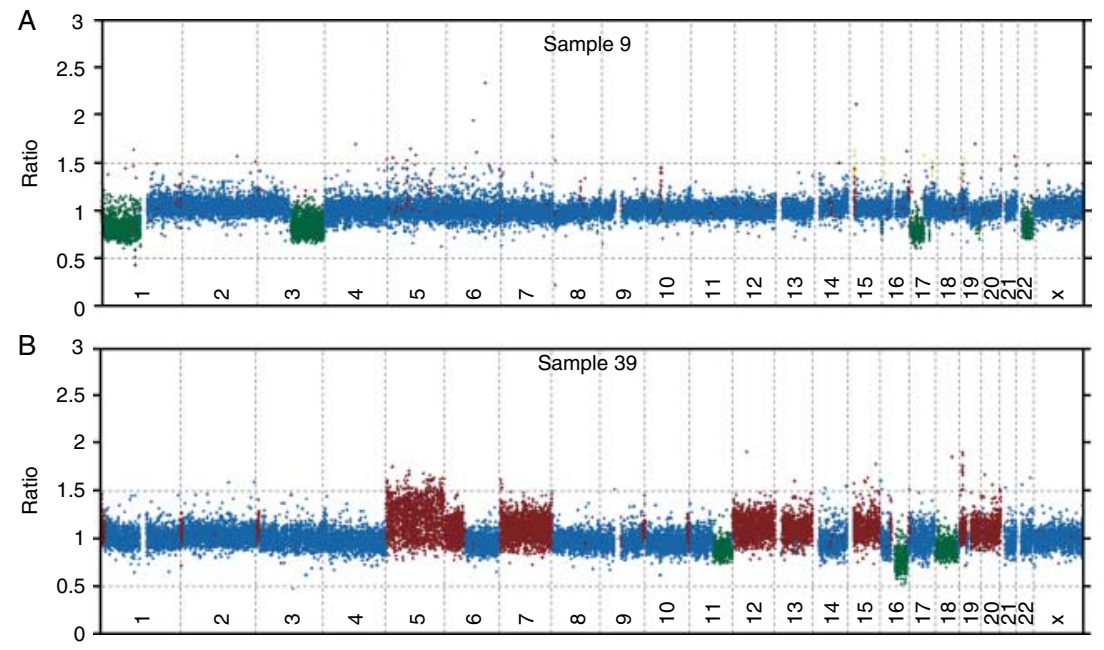

Figure 1 Whole-genome profiles of a benign (A) and a malignant (B) adrenal pheochromocytoma presenting characteristic alterations. The benign sample 9 showed loss of chromosome arms $1 p, 3 q$ and 17p, and monosomy 22 . The small homozygous deletion at 1 p21.1 represents a region of reported genomic variation (\# 611, Database of Genomic Variants). The malignant tumour 39 presented with a higher number of aberrations including trisomies $5,7,12,13,15,19$ and 20, as well as deletion of $11 \mathrm{q}$, 16p and the whole chromosome 18. Samples were hybridized on the 32K BAC array using blood-derived DNA from a healthy female as reference. Clones scored as gained, deleted or with no copy number imbalances are represented by red, green and blue spots respectively. The $X$-axis shows the genomic position of the clones along each chromosome, and the $Y$-axis shows the fluorescence ratio. 

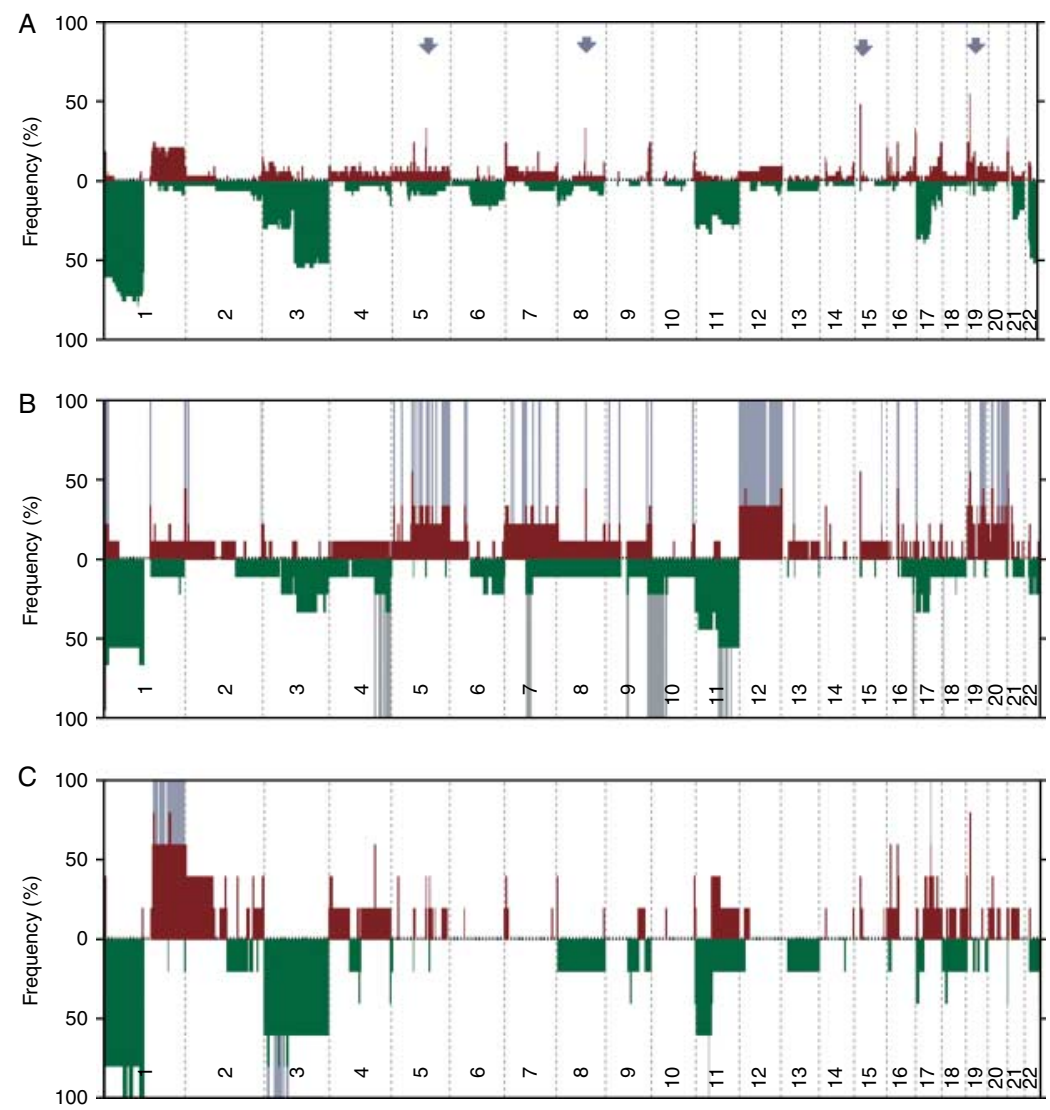

Figure 2 Frequency plots for all the analysed 33 benign (A) and 9 malignant (B) adrenal pheochromocytomas as well as for 5 malignant paragangliomas (C). The frequency of copy number gain and loss was calculated for each individual autosomal clone, and was plotted relative to the position along the chromosomes, which are shown as red and green bars respectively. Frequently reported genomic variants (polymorphisms) are indicated with arrows in A. Grey shadows indicate regions with significantly different frequency of gain or loss between malignant and benign pheochromocytomas $(B)$ and between malignant pheochromocytomas and malignant paragangliomas (C) according to Fisher's exact test, $P<0.05$.

chromosome arm $1 \mathrm{p}$ (79\% of cases) followed by loss of $22 \mathrm{q}(52 \%), 3 \mathrm{q}(48 \%), 17 \mathrm{p}(39 \%)$ and $11 \mathrm{p}(33 \%)$. Gains were less frequent in this group with chromosome arm 1q being the most often affected region (24\%). For malignant pheochromocytomas, loss of chromosome arms $1 \mathrm{p}$ and $11 \mathrm{q}$ was the most frequent alteration, with the loss occurring in $56 \%$ of the cases. Additional recurrently deleted regions included $3 q$ and $11 p(44 \%$ each) as well as $3 p, 4 q$ and $17 p$ (33\% each). Frequently gained chromosomal regions included $19 \mathrm{q}$ arm and whole chromosome 12 (33\% each), as well as whole chromosome 7, 5q and $20 \mathrm{q}$ arms (22\% for all three chromosomes). For the malignant paragangliomas, recurrent aberrations included loss of $1 \mathrm{p}(80 \%)$ followed by loss of $3 q$ and $11 p$ (both 60\%). Sequencing analysis of all paragangliomas and all malignant pheochromocytomas showed that inactivation of the tumour suppressor gene $S D H B$ occurred in four of the seven malignant paragangliomas (samples 47,
48, 50 and 52) and in one of the two benign paragangliomas (sample 35) by mutation of one allele (Table 2) and loss of the other (1p36). Gain of 1q arm was highly frequent (60\%) in the group of malignant paragangliomas as well as gain of $2 p(40 \%), 11 q(20 \%)$ and $4 \mathrm{p}(20 \%)$. We confirmed several of these aberrations using qPCR (Supplementary Table S1, see section on supplementary data given at the end of this article).

\section{Minimal overlapping regions of copy number change in pheochromocytomas}

Defining minimal overlapping regions (MORs) of copy number change may reveal genes that are important for tumour development. MORs including at least three samples were therefore determined in the series of 44 pheochromocytomas (Table 3). The most frequently occurring MORs were found on 


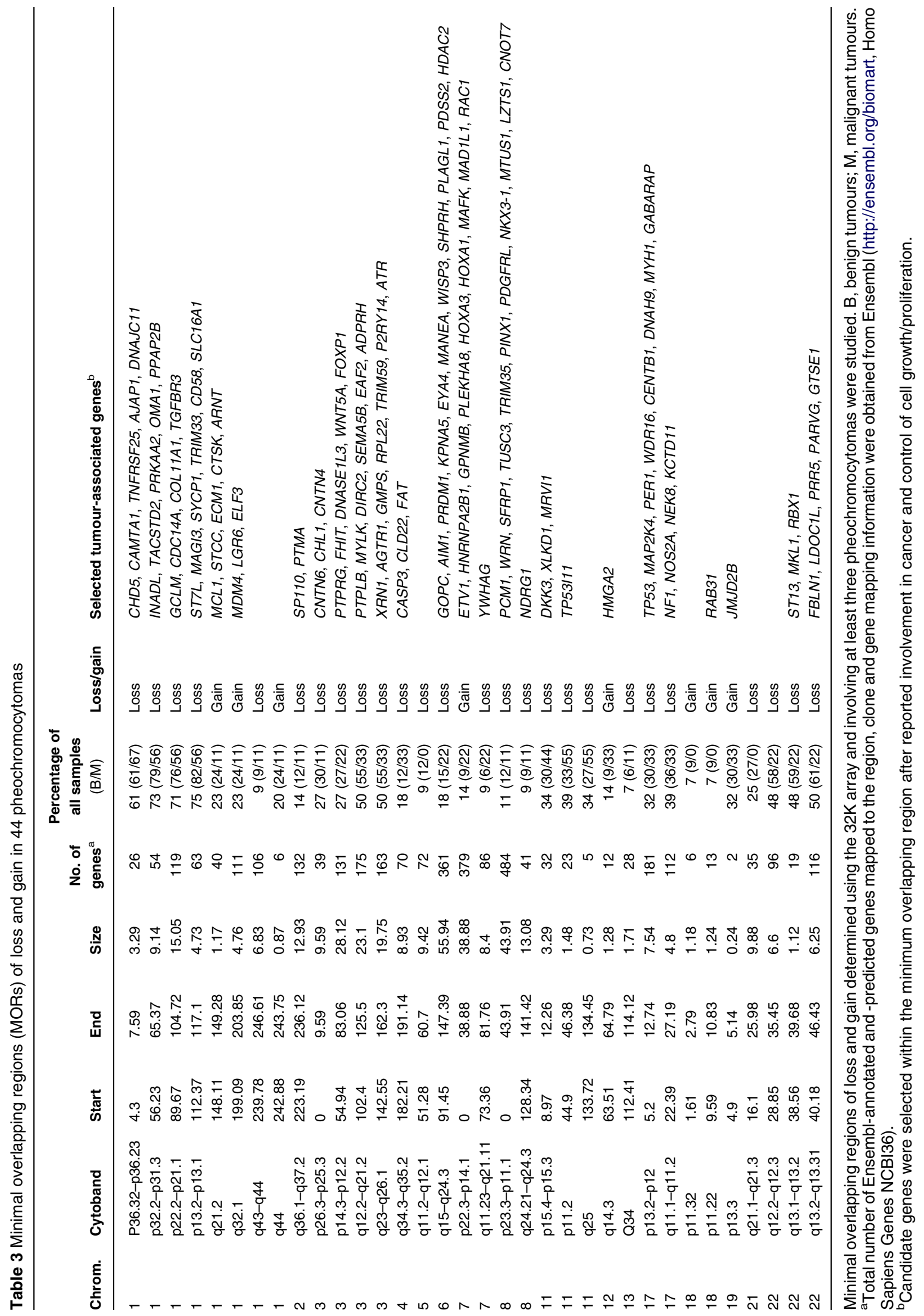


chromosomes 1, 3, 11, 17 and 22 (Supplementary Table S2, see section on supplementary data given at the end of this article). Four MORs of deletion were identified on chromosome arm 1p (Supplementary Figure S2, see section on supplementary data given at the end of this article). The most commonly affected region mapped to $1 \mathrm{p} 13$, and was observed in $75 \%$ of the tumours (Fig. 3). Within this locus, $4.73 \mathrm{Mb}$ in size, STL7 constituted one potentially important gene. The remaining three MORs at $1 \mathrm{p}$ also occurred frequently in the analysed pheochromocytomas (61-73\%), and included chromosomal regions with several candidate tumour suppressor genes. The smallest MOR at $1 \mathrm{p} 36$ included among others the candidate tumour suppressor genes CHD5, CAMTA1 and TNFRSF25 (Fig. 3).

The whole chromosome arm $3 \mathrm{q}$ was frequently deleted, but rarely presented with interstitial loss. Consequently, two relatively large MORs of deletion were identified, 23.1 and $19.7 \mathrm{Mb}$ in size, harbouring 175 and 163 genes respectively (Supplementary Figure S3, see section on supplementary data given at the end of this article). Chromosome 11 was also frequently deleted, and three small MORs of loss were identified on this autosome (Supplementary Figure S4, see section on supplementary data given at the end of this article). The tumour suppressor gene DKK3 mapped to one of these regions. Chromosome 17 included two frequent MORs of deletion, and among the many genes encompassed within these regions, the well-known tumour suppressor genes NF1 and TP53 were found (Supplementary Figure S5, see section on supplementary data given at the end of this article). Losses on chromosome arm 22q were present in $\sim 50 \%$ of the pheochromocytomas, and three MORs were identified (Supplementary Figure S6, see section on supplementary data given at the end of this article). The MOR at 22q13 spanned over $6.25 \mathrm{Mb}$ and included the tumour-associated gene PRR5, and the smallest MOR on this autosome at 22q13 harboured 19 genes with ST13 representing an interesting candidate. MORs of gain were less commonly found in the series of pheochromocytomas. The most frequent, present in $32 \%$ of the samples, and also the smallest $(0.24 \mathrm{Mb})$ tumour-specific MOR of gain, mapped to $19 \mathrm{p} 13.3$ and included only two genes, $J M J D 2 B$ and the hypothetical protein LOC1001284439 (Table 3). Finally, two common MORs of gain, both present in $23 \%$ of the pheochromocytomas, were identified on 1q arm. The MOR mapping to 1q21.2 is shown in Fig. 4, and harbours, for example, the gene CTSK.

\section{Several chromosomal regions were more frequently altered in malignant pheochromocytomas}

From the frequency plot displayed in Fig. 2, it is evident that when the malignant and benign
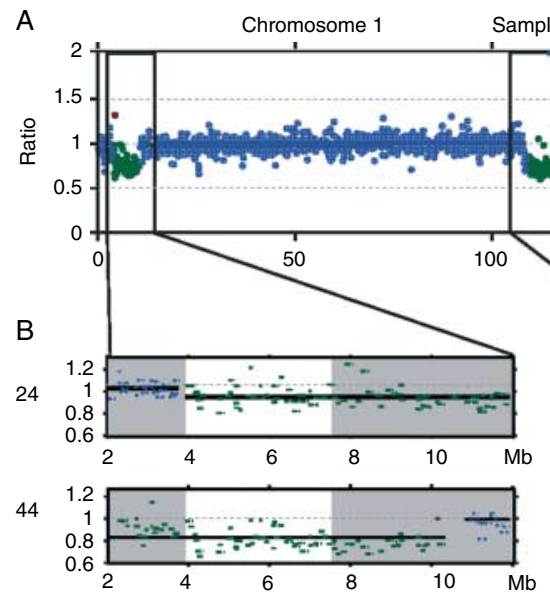

ample 44
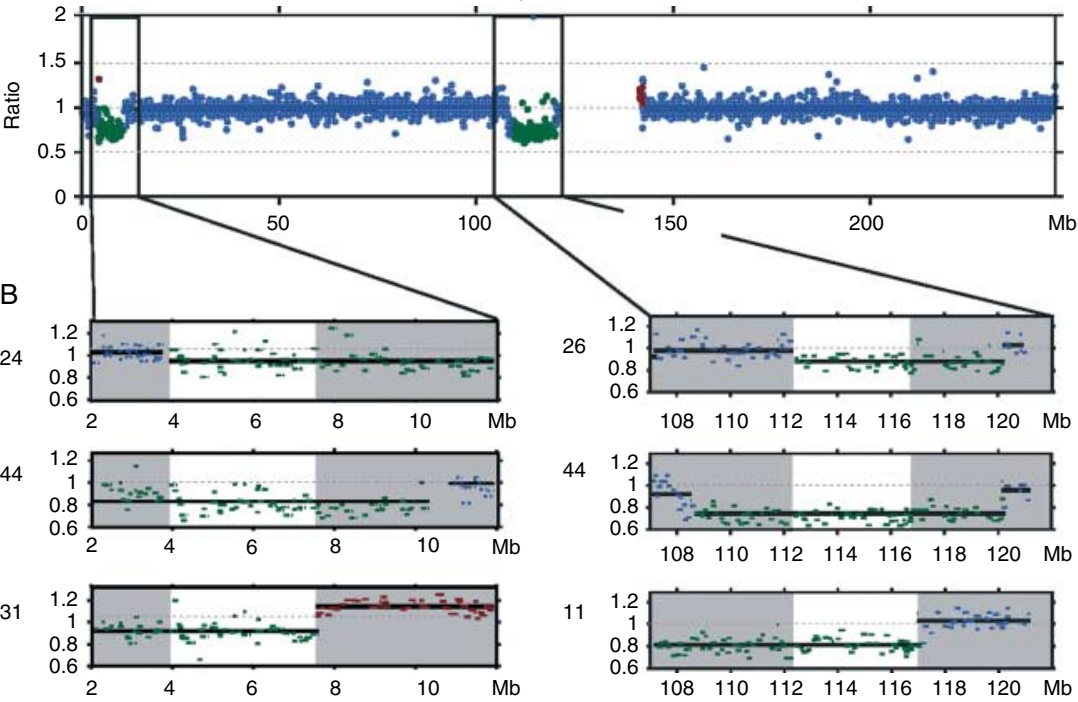

Figure 3 MORs of deletion most frequently identified in pheochromocytomas. Chromosome 1 profile of tumour sample 44 displaying two interstitial deletions (A). These deletions are enlarged in the middle panels below (B). The start and end of the MOR at 1 p36 are defined by sample 24 and 31 respectively, and this MOR encompasses $3.29 \mathrm{Mb}$ (Chr 1: 4.30-7.59 Mb). The MOR located at the proximity of the centromere at $1 \mathrm{p} 13.2$ is determined by samples 26 and 11 . This MOR of $4.73 \mathrm{Mb}(\mathrm{Chr} 1: 112.37-117.10 \mathrm{Mb})$ was the most frequently deleted region in the tumour series. 

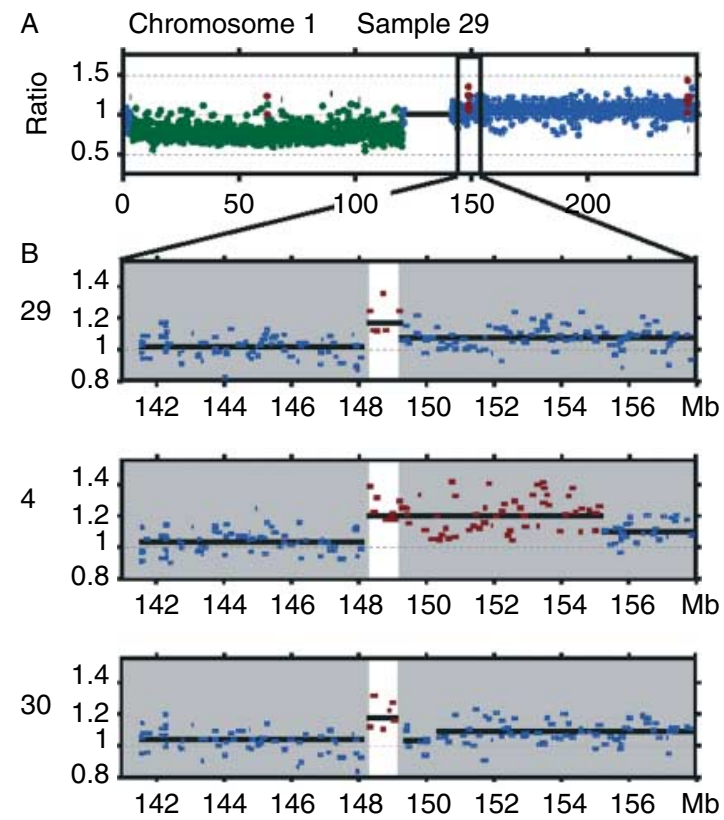

C

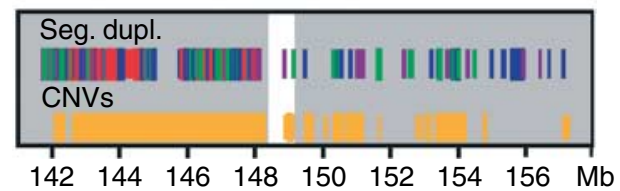

Figure 4 MOR of gain identified in pheochromocytomas. Chromosome 1 profile in tumour 29 (A) revealing a distinct locus with an increase in copy number that is enlarged in the panel below (B). Alignment of two additional representative profiles (4 and 30 ) showing aberrations at this locus (148.11-149.28 Mb) also highlights the shared centromeric breakpoint. This $1.17 \mathrm{Mb}$ sized region at $1 \mathrm{q} 21.2$ is boarded by segmental duplications and reported copy number variants, as depicted in the lower panel (C). No alterations in this region were found in the corresponding blood or normal tissues of the patients.

pheochromocytomas were compared, no chromosomal regions appeared to be exclusively and recurrently altered in either group. However, the malignant samples in general displayed a higher frequency of aberrations, especially gains. To identify which BAC clones were more often involved in copy number imbalances in malignant tumours than in benign ones, we performed Fisher's exact test. The number of BAC clones more frequently gained and deleted in malignant cases was 526 and 348 respectively. The affected regions were often large and spanned over whole chromosomes or chromosome arms, indicated in grey in Fig. 2B. The most overrepresented gained regions in malignant pheochromocytomas were $12 p$ and $19 q$, events present in $33 \%$ of these tumours compared with 3 and $9 \%$ in the benign ones. Gain of $20 \mathrm{q}$ and trisomy 7 were also more commonly observed in the malignant tumours
(22 vs 6\%). Deletion of 11q was the alteration with the highest frequency difference between malignant and benign pheochromocytomas, observed in 56 vs $24 \%$ of samples respectively. Terminal deletions on the long arm of chromosome 4 were also more commonly observed in malignant tumours (33 vs 12\%). Loss of chromosome arms 10p and 9p occurred in 22 and $11 \%$ of malignant samples, while no large deletions were observed in benign cases on either of these autosomes. Noteworthy was that the two questionably benign pheochromocytomas (samples 36 and 37) presented with a high number of alterations (Table 1). Malignant disease was not detected after follow-up of 11 and 5 years respectively.

We also sought to determine if genes located within differentially altered chromosomal regions, derived from the malignant group compared with the benign group, were involved in particular biological processes. A total of 465 genes mapping to the more frequently gained loci and 159 genes encompassed within the more frequently deleted regions in the malignant pheochromocytomas were submitted to the web-based GO tool DAVID. The enriched GO terms are given in Supplementary Tables S3 and S4, see section on supplementary data given at the end of this article. GO biological processes for genes encompassed within the regions more frequently gained in the malignant tumours included regulation of gene expression, response to oxidative stress and signal transduction. Possible candidate genes with oncogenic properties associated within the enriched GO terms included CIC (19q13.2), HMGA2 (12q15), TPO (2p25), EEF1A2 (20q13.3) and PTK6 (20q13.3). Biological processes over-represented for genes encompassed within regions more often deleted in malignant pheochromocytomas comprised metabolic processes and chromatin modification, and this included the gene inhibitor of growth (ING2) (4q35) represented within the latter term. Other genes were the possible tumour suppressor gene $P P P 2 R 1 B$, located in the most frequently deleted region at $11 \mathrm{q} 23.2$, and the DCLRE1C gene located at 10p13.

\section{1q was the most frequently gained region in malignant paragangliomas compared to malignant pheochromocytomas}

We also compared the genomic profiles of primary malignant paragangliomas $(n=5)$ versus primary malignant pheochromocytomas $(n=9)$. Most of the 73 BAC clones that were more often gained in malignant paragangliomas mapped to chromosome arm 1q (Fig. 2C). Gain of 1q was detected with the 
highest frequency difference (49\%), and was found in three of five malignant paragangliomas compared with one of nine malignant pheochromocytomas. Gain of both chromosomal regions $2 \mathrm{p}$ and $11 \mathrm{q} 13$ was present in two samples versus one sample, a frequency difference of $29 \%$. A total of 104 BAC clones were more often found to be deleted in malignant paragangliomas, representing regions on $1 \mathrm{p}$ and $3 \mathrm{p}$ (Fig. 2C). All malignant paragangliomas presented with entire or partial deletions of $1 \mathrm{p}$ compared with $56 \%$ of the malignant pheochromocytomas.

The most overrepresented biological processes derived from the GO analysis of the 114 genes encompassed within the more often gained clones in malignant paragangliomas versus malignant pheochromocytomas according to Fisher's exact test included regulation of biological process, cell proliferation and immune response (Supplementary Table S5, see section on supplementary data given at the end of this article). Interestingly, the gene $C K S 1 B(1 \mathrm{q} 21)$ was found in the enriched GO terms. $C K S 1 B$ is gained and overexpressed in malignant breast cancer, and has also been shown to promote prostate cancer and has been associated with poor prognosis in myeloma (Zhan et al. 2007, Lan et al. 2008, Wang et al. 2009). Also, rather few genes (156) were located in the more often deleted regions, and GO analysis of these revealed cation homeostasis, G-protein signalling and response to external stimuli as some of the biological processes (Supplementary Table S6, see section on supplementary data given at the end of this article). Candidate tumour suppressor genes among the GO terms include NPRL2 and FUS1, both of which are located at $3 \mathrm{p} 21$ and implicated in lung cancer, for instance (Li et al. 2004, Prudkin et al. 2008).

As we had collected both the primary tumour and the corresponding metastases from two patients diagnosed with malignant paraganglioma, a comparison of their DNA copy number profiles was done (Supplementary Figure S7, see section on supplementary data given at the end of this article). The loss of chromosome arms $1 p$ and $3 q$ as well as gain of $1 q$ and $2 p$ was common for all four samples, possibly indicating early events in tumourigenesis. In one patient, the investigated metastasis had acquired more alterations (sample 53 vs 51), pointing to the accumulation of additional genetic damage during tumour evolution. In the other case (sample 52 versus sample 50), the metastasis sample also shared many aberrations with the primary tumour, but a few differences (lack and presence of supplementary aberrations) could be observed. This indicates that the metastasis probably derived from a specific subclone, and that additional mutations subsequently occurred both in the primary tumours and in the metastatic tumours. These tumours (50 and 52) had acquired biallelic inactivation of the $S D H B$ tumour suppressor gene by mutation (Table 2) and loss of $1 \mathrm{p}$.

\section{Discussion}

This study presents a high-resolution genome-wide analysis of DNA copy number changes in 44 pheochromocytomas, 9 paragangliomas and 36 corresponding blood or normal tissues. On average, patients with benign tumours were followed up for 124 months (range 16-240). By applying a whole-genome clonebased array, we were able to identify a number of new candidate chromosomal regions. MORs of deletion or gain were identified on 16 chromosomes, with the most frequent MORs of deletion occurring on chromosomes $1,3,11,17$ and 22, and MORs of gain occurring on chromosomes $1,7,12,18$ and 19.

Loss of whole or part of chromosome arm $1 \mathrm{p}$ was the most frequent aberration detected in 40 of 53 cases (76\%). This implies that inactivation of specific tumour suppressor genes on this chromosome is probably an initial event during the molecular pathogenesis of these tumours. This finding is in agreement with previous CGH and LOH studies (Bender et al. 2000, Dannenberg et al. 2000, Edstrom et al. 2000, August et al. 2004). We could determine four distinct MORs of deletion on $1 \mathrm{p}$ in the series of pheochromocytomas (Table 3, Fig. 3 and Supplementary Figure S2), each including possible tumour suppressor genes. These regions overlap with MORs reported by others, and enabled the narrowing down of loci of interest (Dannenberg et al. 2000, Edstrom et al. 2000, Cascon et al. 2005, Aarts et al. 2006). The most frequent MOR of deletion at $1 \mathrm{p} 13.2-1 \mathrm{p} 13.1$ was present in $75 \%$ of the investigated samples, and contained among others the $S T 7 L$ gene, which is homologous to the tumour suppressor gene ST7. Allelic loss or rearrangements of region $1 \mathrm{p} 13$ have been reported in many human neoplasias, and changes in ST7L expression levels have also been correlated with metastatic progression in melanoma (Riker et al. 2008). The MORs $1 \mathrm{p} 13.2-1 \mathrm{p} 13.1$ and $1 \mathrm{p} 22.2-1 \mathrm{p} 21.1$ identified here were both included in larger candidate regions as defined by using a chromosome 1-specific BAC array on a set of both sporadic and familial pheochromocytomas (Aarts et al. 2006). CDC14A located at $1 \mathrm{p} 21$ encodes a tyrosine phosphatase involved in the exit from cell mitosis and initiation of DNA replication. Interestingly, reduced expression of $C D C 14 A$ has been shown to induce mitotic defects (Mailand et al. 2002). Moreover, CDC14A has also been shown to be 
differentially expressed in human cancer cells and to interact with the tumour suppressor p53 (Paulsen et al. 2006). The transforming growth factor- $\beta$ receptor type III gene $(T G F \beta R 3)$ at $1 \mathrm{p} 22$ is also a possible candidate. Low expression of $T G F \beta R 3$ has been shown in renal cell carcinoma (Copland et al. 2003), and down-regulation of this gene also seems to be of importance in the progression of prostate and breast cancers (Dong et al. 2007, Sharifi et al. 2007). We also defined a small MOR at 1p36.32-p36.23, a region deleted in several human cancers. Chromodomain helicase DNA-binding protein 5 (CHD5) has recently been described as a novel candidate tumour suppressor gene at this locus (Bagchi \& Mills 2008). Moreover, CHD5 was found to be epigenetically silenced by DNA methylation in neuroblastoma cell lines, further supporting a tumour suppressor function (Fujita et al. 2008).

Loss of $3 q$ also occurred frequently in the studied set of pheochromocytomas (48\%), indicative of an early event following $1 \mathrm{p}$ loss (Table 3 and Supplementary Figure S3). Furthermore, deletion of 3q appeared more commonly in benign pheochromocytomas than in malignant pheochromocytomas, and this finding is in agreement with previous studies (Bender et al. 2000, Dannenberg et al. 2000, Edstrom et al. 2000, August et al. 2004, Cascon et al. 2005). Deletions on chromosome 22 were common $(50 \%)$ in pheochromocytoma (Table 3 and Supplementary Figure S6), a result consistent with our previous report (Jarbo et al. 2006). Loss of $22 \mathrm{q}$ was also more frequent in benign tumours than in malignant tumours, and for all but one pheochromocytoma, 22q deletion was combined with $1 \mathrm{p}$ loss. The latter finding was also detected by van Nederveen et al. (2009). An interstitial deletion present in one sample defined a MOR of deletion of $1.1 \mathrm{Mb}$ at $22 q 13.1-22 q 13.2$, which was observed in $48 \%$ of benign tumours. This region harbours several genes, for instance, ST13 (suppression of tumourigenicity 13), which encodes a cofactor of the heat shock protein 70 . ST13 has been found to be down-regulated in gastric and colorectal cancers (Shi et al. 2007), and a potent antitumour effect of ST13 has recently been reported in vitro and in an animal model of colorectal carcinoma (Yang et al. 2008). A second MOR of deletion at 22q13.2-22q13.31 involved $50 \%$ of the tumour samples. This region includes PRR5, which was reported to be down-regulated in breast cancer (Johnstone et al. 2005).

One of the two frequently deleted regions on chromosome 17 (17p13.2-17p12) contains the wellknown tumour suppressor gene TP53 (Table 3 and Supplementary Figure S5). The role of TP53 in pheochromocytoma development is, however, ambiguous. While a recent CGH study has reported frequent loss of the TP53 locus (45\%), no mutations could be detected in exons 5-8 (Petri et al. 2008). Additional studies demonstrated that aberrant expression and mutations of TP53 are rare in pheochromocytoma (Petri et al. 2008). Other tumour suppressor genes in this frequently deleted region may be of importance in pheochromocytoma development. MAP2K4, located $\sim 4 \mathrm{Mb}$ downstream of TP53, could be a candidate gene since loss-of-function mutations have been found at a fairly consistent rate $(\sim 5 \%)$ in primary tumours of the pancreas, bile duct, breast, colon, lung and testis (Cunningham et al. 2006a). Moreover, the lack of expression of MAP2K4 in gastric adenocarcinoma has been shown to be associated with poor survival (Cunningham et al. 2006b). The NF1 gene was included in the second candidate region on chromosome 17 (17q11.1-17q11.2), deleted in 39\% of pheochromocytomas. This gene is of interest since $\sim 5 \%$ of patients with the NF1 syndrome develop pheochromocytoma. However, mutations in this gene as well as in the five other genes known to cause susceptibility to familial pheochromocytoma/paraganglioma are rare in truly sporadic tumours (Dannenberg et al. 2003). The genes VHL (3p25), SDHD (11q23), $S D H B$ (1p36), SDHC (1q21) and RET (10q11.2) as well as the newly identified paraganglioma-associated SDH5 gene (11q13) were not represented within the MORs recognized in the present study.

Chromosome 11 often presented with deletions in the pheochromocytomas. Interestingly, tumours that did not show $1 \mathrm{p}$ loss frequently demonstrated aberrations on chromosome 11 (9 of 11 samples, Table 1 and Supplementary Figure S1), and one tumour presented with $11 \mathrm{q}$ deletion as the only aberration. Three MORs of deletion with frequencies of 34-39\% were defined on this autosome (Table 3 and Supplementary Figure S4). One of the several candidate genes located within the MOR at $11 \mathrm{p} 15.4-11 \mathrm{p} 15.3$ was $D K K 3$. This potential tumour suppressor gene has been found to be down-regulated in various cancers and also epigenetically silenced in gastrointestinal tumours (Sato et al. 2007). TP53-inducible protein 11 (TP53111), situated in a smaller sized MOR at $11 \mathrm{p} 11.2$, is also an interesting candidate gene since a role in promoting apoptosis and low protein expression has been reported in hepatocellular carcinoma cell lines (Ricketts et al. 2003). The observation of two subgroups of sporadic pheochromocytoma, one group with loss of $1 p$ and/or $3 q$ and a second group with loss of $3 p$ with or without $11 \mathrm{p}$ loss as reported by van Nederveen et al. (2009), was not obvious in our set of analysed tumours. Only two 
tumours with no $1 p$ or $3 q$ loss showed loss of $3 p$, both in combination with $11 \mathrm{p}$ deletions.

A small MOR of gain at 19p13.3 was identified in $32 \%$ of the pheochromocytomas. This region encodes $J M J D 2 B$ and the hypothetical protein LOC1001 284439. JMJD2B functions as a demethylase of lysine 9 on histone 3 (Fodor et al. 2006). Trimethylation of lysine 9 on histone 3 has been mostly associated with gene repression of heterochromatin, but also with active expression of genes recently (Wiencke et al. 2008). An altered expression of $J M J D 2 B$ could possibly influence the activity of genes regulated by this epigenetic marker, and subsequently have implications in cancer. In agreement with the array CGH result, immunohistochemistry revealed prominent expression of JMJD2B (data not shown). Gains at 1q were also relatively frequent (23\%), and two MORs were identified on this arm, one at 1q21 where the CTSK gene is located (Fig. 4) and the other at 1q32, harbouring among others the MDM4 gene. These genes deserve attention as expression of CTSK has been linked with invasiveness in breast cancer (Kleer et al. 2008), and the MDM4 locus has recently been found to be amplified in bladder cancer, with associated overexpression of MDM4 and disruption of TP53 activity (Veerakumarasivam et al. 2008).

In the present study, we also focused on recognizing genetic alterations that could be more specific for the malignant samples. The WHO classification defines malignancy of pheochromocytomas and paragangliomas by the presence of metastases, and there is currently no consensus to determine malignancy before metastases occur. Many pathologists consider obvious invasion into surrounding tissue of primary or recurrent tumour, or the presence of an extensive tumour thrombosis as evidence of clinical malignancy (as indicated in one sample in the present series), and histological signs (capsular or vascular invasion, extreme cytological atypia and presence of confluent necroses) can be used in different scoring systems together with other parameters to histopathologically discriminate tumours with a higher risk of malignancy (Linnoila et al. 1990, Thompson 2002, Strong et al. 2008, Tischler 2008). In general, the DNA copy number profiles of the benign and malignant pheochromocytomas showed similar frequency of recurrent deletions as well as a wide range of affected chromosomes in both groups. Nevertheless, the malignant samples showed significantly higher number of large alterations than benign tumours ( 6.8 vs 4.9 on average respectively), and especially gains were more commonly found in the malignant pheochromocytomas (2.6 vs 1.2, Table 1). This finding allowed us to speculate that amplification and possible overexpression of oncogenes may be of importance in the transition of benign to malignant tumour, as described in other cancers (Albertson 2006, Heidenblad et al. 2008). Two tumours with benign clinical behaviour at follow-up but with atypical histological features (samples 36 and 37) also displayed high frequency of alterations, including gains, suggestive of potential malignancy or a stage of transition from benign to malignant phenotype. The most overrepresented regions of gain in malignant pheochromocytomas than in benign pheochromocytomas were chromosome arms $12 p$ and $19 q$ followed by gain of $20 \mathrm{q}$ and trisomy 7 , which has been reported previously in malignant pheochromocytomas (August et al. 2004). Loss of chromosome arms 11q, $4 q, 10 p$ and $9 p$ was more frequent in the malignant pheochromocytomas than in the benign pheochromocytomas. A higher incidence of deletions on $11 q$ and $9 p$ has been observed in malignant tumours (Edstrom et al. 2000, August et al. 2004); however, the association of $4 \mathrm{q}$ deletions and 10p loss with the malignant phenotype is novel.

GO analysis of the genes encompassed within regions more often affected in malignant cases than in benign cases revealed several interesting candidates. However, since the regions span large chromosomal segments, many genes could be considered. Among the several candidates represented within the clones, the EEF1A2 and PTK6 genes, both at 20q13.3 and potential oncogenes, were more frequently gained in malignant pheochromocytomas. Up-regulation and amplification of EEF $1 A 2$ have been reported in various cancers, and also correlation to invasion has been observed (Zhu et al. 2007, Sun et al. 2008, Cao et al. 2009). PTK6 has been proposed to promote cell migration and invasion in breast cancer, and aberrant high expression was reported in breast tumours and ovarian cancer (Schmandt et al. 2006, Shen et al. 2008). The $T P O$ gene at $2 \mathrm{p} 25$ is also worthy of attention since increased expression of this gene was associated with malignant thyroid neoplasia (Weber \& Eng 2008). Other genes of interest include $C I C$, located at the frequently (33\%) gained region on 19q13.2. Significant expression of CIC has been detected in medulloblastoma, and a fusion between $C I C$ and the DUX4 gene, $\mathrm{t}(4 ; 19)(\mathrm{q} 35 ; \mathrm{q} 13)$, has been found in Ewing-like sarcoma (Lee et al. 2005, Kawamura-Saito et al. 2006). Also, the $H M G A$ gene at $12 \mathrm{q} 15$ was overrepresented in the GO analysis and frequently gained. This gene is overexpressed in many tumours, such as lung cancer and salivary gland adenomas (Di Cello et al. 2008, Persson et al. 2009). 
Fewer regions and subsequently fewer genes were more often found to be deleted in malignant pheochromocytomas than in benign pheochromocytomas. However, since the regions were large, a high number of genes could be considered. An interesting gene mapping to the frequently deleted (56\%) chromosome arm 11q is the candidate tumour suppressor gene $P P P 2 R 1 B$ (11q23.2). Mutation of this gene was reported in colon cancer, and it has been shown to be inactivated in CML (chronic myelogenous (or myeloid) leukemia) (Takagi et al. 2000, Neviani et al. 2005). ING2 is an additional tumour suppressor gene that is located at the commonly deleted $(36 \%)$ region at $4 \mathrm{q} 35$. This gene is a member of the ING family. Members of the ING family associate with and modulate the activity of histone acetyltransferase and histone deacetylase complexes and function in DNA repair and apoptosis. Decreased expression of ING2 has been reported in hepatocellular carcinoma, lung cancer and melanoma, for instance (Ythier et al. 2008, Zhang et al. 2008), and frequent LOH at ING2 locus has also been reported in head and neck squamous carcinoma (Borkosky et al. 2009). The DCLRE1C gene (10p13) is included in some of the enriched biological process categories from the $\mathrm{GO}$ analysis, since chromosome 10 loss is overrepresented in the malignant cases. DCLRE1 has a function in DNA repair.

Five primary malignant paraganglioma samples were included in this study (Table 1). These tumours showed similar recurrent aberrations with a very high frequency of $1 \mathrm{p}$ loss (80\%), and regions between $1 \mathrm{p} 13$ and 1 p22 were deleted in all samples. This chromosome arm has also previously been found to be frequently deleted in malignant paragangliomas (Edstrom et al. 2000, Cascon et al. 2005). However, the frequency of $1 \mathrm{p}$ loss reported by Cascon et al. (2005) was lower $(50 \%)$. This could be due to the fact that the paragangliomas analysed in that study were derived from head and neck, and the ones profiled here were of abdominal origin, or possibly that the tumour cell content was higher in our samples. We also detected higher frequency of $3 q$ and $11 p$ deletions (both $60 \%$ ) as well as 1q, 2p and 11q13 gains (60 and $40 \%$ respectively) in malignant paragangliomas, than those reported previously in head and neck paragangliomas (Cascon et al. 2005). These findings indicate that slightly different routes of chromosomal alterations may operate in malignant abdominal paragangliomas than in the head and neck paragangliomas, although clearly larger number of tumours need to be analysed.
The identification of distinct and narrow candidate chromosomal regions of frequent loss and gain on several autosomes in the present study, including loci on highly frequently deleted $1 \mathrm{p}$ arm, is of great importance since these may harbour candidate tumour genes involved in the development and progression of pheochromocytomas. Furthermore, our results highlight chromosomal regions more frequently affected by alterations in malignant pheochromocytomas and malignant paragangliomas. The fact that gains are over-represented may suggest the importance of oncogene overexpression in the malignant tumours. These findings may shed light on the molecular mechanisms involved in the development of malignant pheochromocytomas as well as aid in the search for novel markers of malignancy.

\section{Supplementary data}

This is linked to the online version of the paper at http://dx. doi.org/10.1677/ERC-09-0310.

\section{Declaration of interest}

The authors declare that there is no conflict of interest that could be perceived as prejudicing the impartiality of the research reported.

\section{Funding}

This study was supported by the Swedish Cancer Society (T D de Ståhl, J P Dumanski, C Larsson and G Åkerström), Swedish Research Council (G Westin and C Larsson), Swedish Children Cancer Fund (T D de Ståhl), Göran Gustafson Foundation for Research in Natural Science and Medicine (C Larsson), and Gustav V Jubilee Foundation (C Larsson).

\section{Acknowledgements}

We are grateful to B Bondeson and P Lillhager for their skilful technical assistance. We thank Lars Grimelius for histopathological examination.

\section{References}

Aarts M, Dannenberg H, deLeeuw RJ, van Nederveen FH, Verhofstad AA, Lenders JW, Dinjens WN, Speel EJ, Lam WL \& de Krijger RR 2006 Microarray-based CGH of sporadic and syndrome-related pheochromocytomas using a $0.1-0.2 \mathrm{Mb}$ bacterial artificial chromosome array spanning chromosome arm 1p. Genes, Chromosomes \& Cancer 45 83-93.

Albertson DG 2006 Gene amplification in cancer. Trends in Genetics 22 447-455. 
Ameur A, Yankovski V, Enroth S, Spjuth O \& Komorowski J 2006 The LCB Data Warehouse. Bioinformatics 22 1024-1026.

Andersson R, Bruder CE, Piotrowski A, Menzel U, Nord H, Sandgren J, Hvidsten TR, Diaz de Stahl T, Dumanski JP \& Komorowski J 2008 A segmental maximum a posteriori approach to genome-wide copy number profiling. Bioinformatics 24 751-758.

Astuti D, Douglas F, Lennard TW, Aligianis IA, Woodward ER, Evans DG, Eng C, Latif F \& Maher ER 2001a Germline SDHD mutation in familial phaeochromocytoma. Lancet 357 1181-1182.

Astuti D, Latif F, Dallol A, Dahia PL, Douglas F, George E, Skoldberg F, Husebye ES, Eng C \& Maher ER 2001b Gene mutations in the succinate dehydrogenase subunit SDHB cause susceptibility to familial pheochromocytoma and to familial paraganglioma. American Journal of Human Genetics 69 49-54.

August C, August K, Schroeder S, Bahn H, Hinze R, Baba HA, Kersting C \& Buerger H 2004 CGH and CD 44/MIB-1 immunohistochemistry are helpful to distinguish metastasized from nonmetastasized sporadic pheochromocytomas. Modern Pathology 17 1119-1128.

Bagchi A \& Mills AA 2008 The quest for the 1p36 tumor suppressor. Cancer Research 68 2551-2556.

Baysal BE, Ferrell RE, Willett-Brozick JE, Lawrence EC, Myssiorek D, Bosch A, van der Mey A, Taschner PE, Rubinstein WS, Myers EN et al. 2000 Mutations in SDHD, a mitochondrial complex II gene, in hereditary paraganglioma. Science 287 848-851.

Bender BU, Gutsche M, Glasker S, Muller B, Kirste G, Eng C \& Neumann HP 2000 Differential genetic alterations in von Hippel-Lindau syndrome-associated and sporadic pheochromocytomas. Journal of Clinical Endocrinology and Metabolism 85 4568-4574.

Borkosky SS, Gunduz M, Nagatsuka H, Beder LB, Gunduz E, Ali MA, Rodriguez AP, Cilek MZ, Tominaga S, Yamanaka N et al. 2009 Frequent deletion of ING2 locus at 4q35.1 associates with advanced tumor stage in head and neck squamous cell carcinoma. Journal of Cancer Research and Clinical Oncology 135 703-713.

Bravo EL \& Tagle R 2003 Pheochromocytoma: stateof-the-art and future prospects. Endocrine Reviews 24 539-553.

Bryant J, Farmer J, Kessler LJ, Townsend RR \& Nathanson KL 2003 Pheochromocytoma: the expanding genetic differential diagnosis. Journal of the National Cancer Institute 95 1196-1204.

Buckley PG, Mantripragada KK, Benetkiewicz M, Tapia-Paez I, Diaz De Stahl T, Rosenquist M, Ali H, Jarbo C, De Bustos C, Hirvela C et al. 2002 A full-coverage, high-resolution human chromosome 22 genomic microarray for clinical and research applications. Human Molecular Genetics 11 3221-3229.
Cao H, Zhu Q, Huang J, Li B, Zhang S, Yao W \& Zhang Y 2009 Regulation and functional role of eEF1A2 in pancreatic carcinoma. Biochemical and Biophysical Research Communications 380 11-16.

Cascon A, Ruiz-Llorente S, Rodriguez-Perales S, Honrado E, Martinez-Ramirez A, Leton R, Montero-Conde C, Benitez J, Dopazo J, Cigudosa JC et al. 2005 A novel candidate region linked to development of both pheochromocytoma and head/neck paraganglioma. Genes, Chromosomes \& Cancer 42 260-268.

Copland JA, Luxon BA, Ajani L, Maity T, Campagnaro E, Guo H, LeGrand SN, Tamboli P \& Wood CG 2003 Genomic profiling identifies alterations in TGFbeta signaling through loss of TGFbeta receptor expression in human renal cell carcinogenesis and progression. Oncogene 22 8053-8062.

Cunningham SC, Gallmeier E, Hucl T, Dezentje DA, Abdelmohsen K, Gorospe M \& Kern SE 2006a Theoretical proposal: allele dosage of MAP2K4/MKK4 could rationalize frequent $17 \mathrm{p}$ loss in diverse human cancers. Cell Cycle 5 1090-1093.

Cunningham SC, Kamangar F, Kim MP, Hammoud S, Haque R, Iacobuzio-Donahue C, Ashfaq R, Kern SE, Maitra A, Heitmiller RE et al. $2006 b$ MKK4 status predicts survival after resection of gastric adenocarcinoma. Archives of Surgery 141 1095-1099.

Dannenberg H, Speel EJ, Zhao J, Saremaslani P, van Der Harst E, Roth J, Heitz PU, Bonjer HJ, Dinjens WN, Mooi WJ et al. 2000 Losses of chromosomes 1p and 3q are early genetic events in the development of sporadic pheochromocytomas. American Journal of Pathology 157 353-359.

Dannenberg H, Komminoth P, Dinjens WN, Speel EJ \& de Krijger RR 2003 Molecular genetic alterations in adrenal and extra-adrenal pheochromocytomas and paragangliomas. Endocrine Pathology 14 329-350.

Di Cello F, Hillion J, Hristov A, Wood LJ, Mukherjee M, Schuldenfrei A, Kowalski J, Bhattacharya R, Ashfaq R \& Resar LM 2008 HMGA2 participates in transformation in human lung cancer. Molecular Cancer Research 6 743-750.

Dong M, How T, Kirkbride KC, Gordon KJ, Lee JD, Hempel N, Kelly P, Moeller BJ, Marks JR \& Blobe GC 2007 The type III TGF-beta receptor suppresses breast cancer progression. Journal of Clinical Investigation 117 206-217.

Edstrom E, Mahlamaki E, Nord B, Kjellman M, Karhu R, Hoog A, Goncharov N, Teh BT, Backdahl M \& Larsson C 2000 Comparative genomic hybridization reveals frequent losses of chromosomes $1 \mathrm{p}$ and $3 \mathrm{q}$ in pheochromocytomas and abdominal paragangliomas, suggesting a common genetic etiology. American Journal of Pathology 156 651-659.

Edstrom Elder E, Hjelm Skog AL, Hoog A \& Hamberger B 2003 The management of benign and malignant pheochromocytoma and abdominal paraganglioma. European Journal of Surgical Oncology 29 278-283. 
Elder EE, Elder G \& Larsson C 2005 Pheochromocytoma and functional paraganglioma syndrome: no longer the $10 \%$ tumor. Journal of Surgical Oncology 89 193-201.

Eng C, Kiuru M, Fernandez MJ \& Aaltonen LA 2003 A role for mitochondrial enzymes in inherited neoplasia and beyond. Nature Reviews. Cancer 3 193-202.

Erickson D, Kudva YC, Ebersold MJ, Thompson GB, Grant CS, van Heerden JA \& Young WF Jr 2001 Benign paragangliomas: clinical presentation and treatment outcomes in 236 patients. Journal of Clinical Endocrinology and Metabolism 86 5210-5216.

Fodor BD, Kubicek S, Yonezawa M, O’Sullivan RJ, Sengupta R, Perez-Burgos L, Opravil S, Mechtler K, Schotta G \& Jenuwein T 2006 Jmjd2b antagonizes $\mathrm{H} 3 \mathrm{~K} 9$ trimethylation at pericentric heterochromatin in mammalian cells. Genes and Development 20 1557-1562.

Fujita T, Igarashi J, Okawa ER, Gotoh T, Manne J, Kolla V, Kim J, Zhao H, Pawel BR, London WB et al. 2008 CHD5, a tumor suppressor gene deleted from 1p36.31 in neuroblastomas. Journal of the National Cancer Institute 100 940-949.

Hao HX, Khalimonchuk O, Schraders M, Dephoure N, Bayley JP, Kunst H, Devilee P, Cremers CW, Schiffman JD, Bentz BG et al. 2009 SDH5, a gene required for flavination of succinate dehydrogenase, is mutated in paraganglioma. Science 325 1139-1142.

Heidenblad M, Lindgren D, Jonson T, Liedberg F, Veerla S, Chebil G, Gudjonsson S, Borg A, Mansson W \& Hoglund M 2008 Tiling resolution array $\mathrm{CGH}$ and high density expression profiling of urothelial carcinomas delineate genomic amplicons and candidate target genes specific for advanced tumors. BMC Medical Genomics 13.

Hughes TR, Roberts CJ, Dai H, Jones AR, Meyer MR, Slade D, Burchard J, Dow S, Ward TR, Kidd MJ et al. 2000 Widespread aneuploidy revealed by DNA microarray expression profiling. Nature Genetics 25 333-337.

Jarbo C, Buckley PG, Piotrowski A, Mantripragada KK, Benetkiewicz M, de Stahl TD, Langford CF, Gregory SG, Dralle H, Gimm O et al. 2006 Detailed assessment of chromosome 22 aberrations in sporadic pheochromocytoma using array-CGH. International Journal Cancer 118 1159-1164.

Johnstone CN, Castellvi-Bel S, Chang LM, Sung RK, Bowser MJ, Pique JM, Castells A \& Rustgi AK 2005 PRR5 encodes a conserved proline-rich protein predominant in kidney: analysis of genomic organization, expression, and mutation status in breast and colorectal carcinomas. Genomics 85 338-351.

Kallioniemi A 2008 CGH microarrays and cancer. Current Opinion in Biotechnology 19 36-40.

Karagiannis A, Mikhailidis DP, Athyros VG \& Harsoulis F 2007 Pheochromocytoma: an update on genetics and management. Endocrine-Related Cancer 14 935-956.

Kawamura-Saito M, Yamazaki Y, Kaneko K, Kawaguchi N, Kanda H, Mukai H, Gotoh T, Motoi T, Fukayama M,
Aburatani H et al. 2006 Fusion between CIC and DUX4 up-regulates PEA3 family genes in Ewing-like sarcomas with $\mathrm{t}(4 ; 19)(\mathrm{q} 35 ; \mathrm{q} 13)$ translocation. Human Molecular Genetics 15 2125-2137.

Kiss NB, Geli J, Lundberg F, Avci C, Velazquez-Fernandez D, Hashemi J, Weber G, Hoog A, Ekstrom TJ, Backdahl M et al. 2008 Methylation of the p16INK4A promoter is associated with malignant behavior in abdominal extra-adrenal paragangliomas but not pheochromocytomas. Endocrine-Related Cancer 15 609-621.

Kleer CG, Bloushtain-Qimron N, Chen YH, Carrasco D, $\mathrm{Hu}$ M, Yao J, Kraeft SK, Collins LC, Sabel MS, Argani P et al. 2008 Epithelial and stromal cathepsin K and CXCL14 expression in breast tumor progression. Clinical Cancer Research 14 5357-5367.

Lan Y, Zhang Y, Wang J, Lin C, Ittmann MM \& Wang F 2008 Aberrant expression of $\mathrm{Cks} 1$ and $\mathrm{Cks} 2$ contributes to prostate tumorigenesis by promoting proliferation and inhibiting programmed cell death. International Journal of Cancer 123 543-551.

Latif F, Tory K, Gnarra J, Yao M, Duh FM, Orcutt ML, Stackhouse T, Kuzmin I, Modi W, Geil L et al. 1993 Identification of the von Hippel-Lindau disease tumor suppressor gene. Science 260 1317-1320.

Lee CJ, Chan WI \& Scotting PJ 2005 CIC, a gene involved in cerebellar development and ErbB signaling, is significantly expressed in medulloblastomas. Journal of Neuro-Oncology 73 101-108.

Li J, Wang F, Haraldson K, Protopopov A, Duh FM, Geil L, Kuzmin I, Minna JD, Stanbridge E, Braga E et al. 2004 Functional characterization of the candidate tumor suppressor gene NPRL2/G21 located in 3p21.3C. Cancer Research 64 6438-6443.

Linnoila RI, Keiser HR, Steinberg SM \& Lack EE 1990 Histopathology of benign versus malignant sympathoadrenal paragangliomas: clinicopathologic study of 120 cases including unusual histologic features. Human Pathology 21 1168-1180.

Mailand N, Lukas C, Kaiser BK, Jackson PK, Bartek J \& Lukas J 2002 Deregulated human Cdc14A phosphatase disrupts centrosome separation and chromosome segregation. Nature Cell Biology 4 317-322.

Mulligan LM, Kwok JB, Healey CS, Elsdon MJ, Eng C, Gardner E, Love DR, Mole SE, Moore JK, Papi L et al. 1993 Germ-line mutations of the RET proto-oncogene in multiple endocrine neoplasia type 2A. Nature $\mathbf{3 6 3}$ 458-460.

van Nederveen F, Korpershoek E, deLeeuw R, Verhofstad AA, Lenders JW, Dinjens WNM, Lam WL \& de Krijger RR 2009 Array-comparative genomic hybridization in sporadic benign pheochromocytomas. Endocrine-Related Cancer 16 505-513.

Neumann HP, Bausch B, McWhinney SR, Bender BU, Gimm O, Franke G, Schipper J, Klisch J, Altehoefer C, Zerres K et al. 2002 Germ-line mutations in nonsyndromic pheochromocytoma. New England Journal of Medicine 346 1459-1466. 
Neumann HP, Pawlu C, Peczkowska M, Bausch B, McWhinney SR, Muresan M, Buchta M, Franke G, Klisch J, Bley TA et al. 2004 Distinct clinical features of paraganglioma syndromes associated with SDHB and SDHD gene mutations. Journal of the American Medical Association 292 943-951.

Neviani P, Santhanam R, Trotta R, Notari M, Blaser BW, Liu S, Mao H, Chang JS, Galietta A, Uttam A et al. 2005 The tumor suppressor PP2A is functionally inactivated in blast crisis CML through the inhibitory activity of the BCR/ABL-regulated SET protein. Cancer Cell $\mathbf{8}$ 355-368.

Niemann S \& Muller U 2000 Mutations in SDHC cause autosomal dominant paraganglioma, type 3. Nature Genetics 26 268-270.

Pasini B \& Stratakis CA 2009 SDH mutations in tumorigenesis and inherited endocrine tumours: lesson from the phaeochromocytoma-paraganglioma syndromes. Journal of Internal Medicine 266 19-42.

Paulsen MT, Starks AM, Derheimer FA, Hanasoge S, Li L, Dixon JE \& Ljungman M 2006 The p53-targeting human phosphatase hCdc14A interacts with the Cdk1/cyclin B complex and is differentially expressed in human cancers. Molecular Cancer 525.

Persson F, Andren Y, Winnes M, Wedell B, Nordkvist A, Gudnadottir G, Dahlenfors R, Sjogren H, Mark J \& Stenman G 2009 High-resolution genomic profiling of adenomas and carcinomas of the salivary glands reveals amplification, rearrangement, and fusion of HMGA2. Genes, Chromosomes \& Cancer 48 69-82.

Petri BJ, Speel EJ, Korpershoek E, Claessen SM, van Nederveen FH, Giesen V, Dannenberg H, van der Harst E, Dinjens WN \& de Krijger RR 2008 Frequent loss of 17p, but no p53 mutations or protein overexpression in benign and malignant pheochromocytomas. Modern Pathology 21 407-413.

Piotrowski A, Bruder CE, Andersson R, de Stahl TD, Menzel U, Sandgren J, Poplawski A, von Tell D, Crasto C, Bogdan A et al. 2008 Somatic mosaicism for copy number variation in differentiated human tissues. Human Mutation 29 1118-1124.

Pollack JR, Sorlie T, Perou CM, Rees CA, Jeffrey SS, Lonning PE, Tibshirani R, Botstein D, Borresen-Dale AL \& Brown PO 2002 Microarray analysis reveals a major direct role of DNA copy number alteration in the transcriptional program of human breast tumors. PNAS 99 12963-12968.

Prudkin L, Behrens C, Liu DD, Zhou X, Ozburn NC, Bekele BN, Minna JD, Moran C, Roth JA, Ji L et al. 2008 Loss and reduction of FUS1 protein expression is a frequent phenomenon in the pathogenesis of lung cancer. Clinical Cancer Research 14 41-47.

Ricketts SL, Carter JC \& Coleman WB 2003 Identification of three $11 \mathrm{p} 11.2$ candidate liver tumor suppressors through analysis of known human genes. Molecular Carcinogenesis 36 90-99.
Riker AI, Enkemann SA, Fodstad O, Liu S, Ren S, Morris C, Xi Y, Howell P, Metge B, Samant RS et al. 2008 The gene expression profiles of primary and metastatic melanoma yields a transition point of tumor progression and metastasis. BMC Medical Genomics 113.

Sato H, Suzuki H, Toyota M, Nojima M, Maruyama R, Sasaki S, Takagi H, Sogabe Y, Sasaki Y, Idogawa M et al. 2007 Frequent epigenetic inactivation of DICKKOPF family genes in human gastrointestinal tumors. Carcinogenesis 28 2459-2466.

Schmandt RE, Bennett M, Clifford S, Thornton A, Jiang F, Broaddus RR, Sun CC, Lu KH, Sood AK \& Gershenson DM 2006 The BRK tyrosine kinase is expressed in high-grade serous carcinoma of the ovary. Cancer Biology \& Therapy 5 1136-1141.

Sharifi N, Lechleider RJ \& Farrar WL 2007 Transforming growth factor-beta receptor III downregulation in prostate cancer: is inhibin B a tumor suppressor in prostate? Journal of Molecular Endocrinology 39 329-332.

Shen CH, Chen HY, Lin MS, Li FY, Chang CC, Kuo ML, Settleman J \& Chen RH 2008 Breast tumor kinase phosphorylates p190RhoGAP to regulate rho and ras and promote breast carcinoma growth, migration, and invasion. Cancer Research 68 7779-7787.

Shi ZZ, Zhang JW \& Zheng S 2007 What we know about ST13, a co-factor of heat shock protein, or a tumor suppressor? Journal of Zhejiang University. Science. B 8 170-176.

de Stahl TD, Sandgren J, Piotrowski A, Nord H, Andersson R, Menzel U, Bogdan A, Thuresson AC, Poplawski A, von Tell D et al. 2008 Profiling of copy number variations (CNVs) in healthy individuals from three ethnic groups using a human genome $32 \mathrm{~K}$ BAC-clone-based array. Human Mutation 29 398-408.

Strong VE, Kennedy T, Al-Ahmadie H, Tang L, Coleman J, Fong Y, Brennan M \& Ghossein RA 2008 Prognostic indicators of malignancy in adrenal pheochromocytomas: clinical, histopathologic, and cell cycle/apoptosis gene expression analysis. Surgery 143 759-768.

Sun Y, Wong N, Guan Y, Salamanca CM, Cheng JC, Lee JM, Gray JW \& Auersperg N 2008 The eukaryotic translation elongation factor eEF1A2 induces neoplastic properties and mediates tumorigenic effects of ZNF217 in precursor cells of human ovarian carcinomas. International Journal of Cancer 123 1761-1769.

Takagi Y, Futamura M, Yamaguchi K, Aoki S, Takahashi T \& Saji S 2000 Alterations of the PPP2R1B gene located at 11q23 in human colorectal cancers. Gut $\mathbf{4 7}$ 268-271.

Thompson LD 2002 Pheochromocytoma of the adrenal gland scaled score (PASS) to separate benign from malignant neoplasms: a clinicopathologic and immunophenotypic study of 100 cases. American Journal of Surgical Pathology 26 551-566. 
Tischler AS 2008 Pheochromocytoma and extra-adrenal paraganglioma: updates. Archives of Pathology \& Laboratory Medicine 132 1272-1284.

Veerakumarasivam A, Scott HE, Chin SF, Warren A, Wallard MJ, Grimmer D, Ichimura K, Caldas C, Collins VP, Neal DE et al. 2008 High-resolution array-based comparative genomic hybridization of bladder cancers identifies mouse double minute 4 (MDM4) as an amplification target exclusive of MDM2 and TP53. Clinical Cancer Research 14 2527-2534.

Wang XC, Tian J, Tian LL, Wu HL, Meng AM, Ma TH, Xiao J, Xiao XL \& Li CH 2009 Role of Cks1 amplification and overexpression in breast cancer. Biochemical and Biophysical Research Communications 379 1107-1113.

Weber F \& Eng C 2008 Update on the molecular diagnosis of endocrine tumors: toward -omics-based personalized healthcare? Journal of Clinical Endocrinology and Metabolism 93 1097-1104.

Wiencke JK, Zheng S, Morrison Z \& Yeh RF 2008 Differentially expressed genes are marked by histone 3 lysine 9 trimethylation in human cancer cells. Oncogene 27 2412-2421.

Xu W, Mulligan LM, Ponder MA, Liu L, Smith BA, Mathew CG \& Ponder BA 1992 Loss of NF1 alleles in phaeochromocytomas from patients with type I neurofibromatosis. Genes, Chromosomes \& Cancer 4 337-342.
Yang M, Cao X, Yu MC, Gu JF, Shen ZH, Ding M, Yu de B, Zheng S \& Liu X 2008 Potent antitumor efficacy of ST13 for colorectal cancer mediated by oncolytic adenovirus via mitochondrial apoptotic cell death. Human Gene Therapy 19 343-353.

Ythier D, Larrieu D, Brambilla C, Brambilla E \& Pedeux R 2008 The new tumor suppressor genes ING: genomic structure and status in cancer. International Journal of Cancer 123 1483-1490.

Zhan F, Colla S, Wu X, Chen B, Stewart JP, Kuehl WM, Barlogie B \& Shaughnessy JD Jr 2007 CKS1B, overexpressed in aggressive disease, regulates multiple myeloma growth and survival through SKP2- and p27Kip1-dependent and -independent mechanisms. Blood 109 4995-5001.

Zhang HK, Pan K, Wang H, Weng DS, Song HF, Zhou J, Huang W, Li JJ, Chen MS \& Xia JC 2008 Decreased expression of ING2 gene and its clinicopathological significance in hepatocellular carcinoma. Cancer Letters 261 183-192.

Zhu H, Lam DC, Han KC, Tin VP, Suen WS, Wang E, Lam WK, Cai WW, Chung LP \& Wong MP 2007 High resolution analysis of genomic aberrations by metaphase and array comparative genomic hybridization identifies candidate tumour genes in lung cancer cell lines. Cancer Letters 245 303-314. 